\title{
Reviews on the Friction Stir Welding Process that Affects Various Parameters
}

\author{
Rasbihari Vishwakarma $^{1}$, Sharda Pratap Shrivas ${ }^{1}$, G K Agrawal $^{2}$, S Nagpal $^{3}$ \\ ${ }^{1}$ Department of Mechanical Engineering, Chouksey Engineering College Bilaspur, 495004, Chhattisgarh \\ ${ }^{2}$ Department of Mechanical Engineering, Government Engineering College Bilaspur, 495009, Chhattisgarh \\ ${ }^{3}$ Department of Mechanical Engineering, Bhilai Institute of Technology Durg 491001, Chhattisgarh \\ Corresponding Author: Email id - rasbihariv@gmail.com
}

\begin{abstract}
A friction stir welding (FSW) is clearly a critical process for the success of welding for aluminum alloys. Many of the common problems of fusion welding are overcome by friction stir welding (FSW), allowing the widespread solid-state welding of soft materials such as aluminum alloys. The commercial achievement of the FSW process is proving to be cost-effective for alloys such as aluminum providing structurally sound welds. Several important aspects of FSW equipment such as tool material selection, geometry and load carrying capacity, thermal behavior, tool reduction mechanism and process economics are discussed in this review. After studying all these important aspects, the high welding strength obtained from welding parameters has also been highlighted.
\end{abstract}

Key Words: - Friction stir welding, tool effect, microstructure, welding strength, welding parameter

\section{Introduction}

The Welding Institute (TWI) pioneered friction stir welding (FSW) in 1991, first for connecting aluminium. Various forums give a complete evaluation of the FSW method. The essential notion of FSW is that a non-consumable spinning tool is utilised, which has been carefully constructed with a geometry that contains pins and shoulders for tool, as illustrated in fig. 1. FSW can create frictional heat and plastic metal flow, resulting in dynamic recrystallization, grain refinement, and second-stage refinement, all of which improve the material's mechanical properties [1]. The high-speed steels tool is one of the most commonly used FSW tools. It can maintain acceptable mechanical qualities under high-speed settings, and its price is lower than that of other tool materials, hence it is frequently employed as an exciter in FSW [2]. Friction stir welding tool used to weld high melting temperature materials such as steels and titanium alloys must be able to handle high shear and impact forces as well as high wear resistance at high temperatures. FSW avoids the main difficulties of fusion welding, such as solidification and liquefaction cracking, porosity, and loss of volatile alloying components, because there is no bulk melting of the work piece. These benefits are the primary reasons for its broad commercial success in welding aluminium and other soft metals. While the above tool materials can be used to make successful welds, the cost of such high-end materials is very high due to the difficulty in manufacturing these tools [3]. 


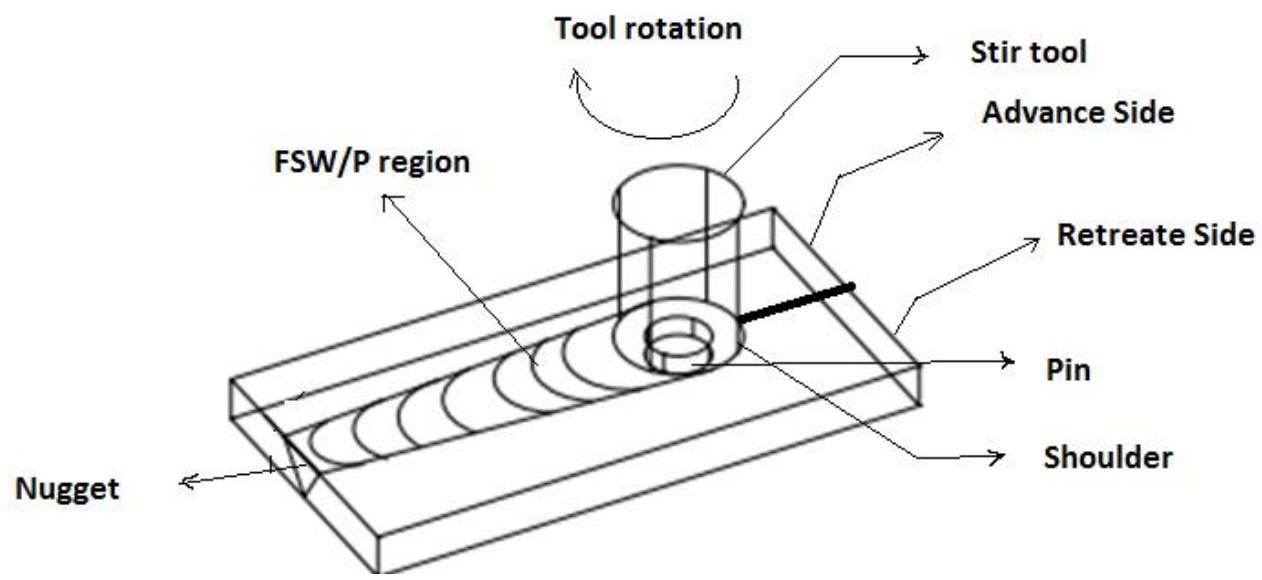

Fig. 1 Schematic Diagram of the friction stir process

\section{Literature Review}

Batalha et al. [1] studied the coating performance of physical vapour deposition (PVD) on Cemented Carbide Tool is employed in Friction Stir Welding for TI Alloy Sheet Processing. Also studied by applying a coating of AlCrN material to Cemented Carbide Tool to improve its wear resistance, thermal shock stability and hot hardness wear. Tool demotion was evaluated for micro-scale microscopy to allow the mechanism of wear to electron core strength to be observed. The actual profitability of the coating layer could not be assessed, as there is no trace of its components in the square tool.

Chen et al. [2] investigated on friction occurring temperature while friction stir welding (FSW) joins the work-piece material. In this work overlaying has affected also observed the interface in the zero-set region and overlaid the forward direction. The resulting composition and micro hardness the sub surface of the coated samples was analysed. Lakshminarayanan et al. [3] studied profile of the FSW tool material is modified by providing refractory composite coatings coated utilising the APS and PTA hard facing techniques. Wrought iron carbide, chromium carbide, boron carbide, titanium carbide, and boron nitride were the carbide powders used for coating and hard facing. Li et al. [4] evaluated friction stir welding process in spindle, where a high amount of heat is produced by a friction stir device, and the welding thermal efficiency is low, resulting in lower welding thermal efficiency and devastating consequences on spindle bearings. In the Heat addition investigation, Finite Element Analytical reproduction for welding tool has been used. Also observed three ways that were discovered based on analytical models and the transfer of heat equipment with the tool holder under the control of this experiment. Fall et al. [5] studied equipment wear rate considering wear rate in FSW during welding according to friction stir and Ti-6Al-4V alloy. The shape of the conical tungsten carbide tool generated the butt-type in this technique, according to observations. The friction stirrer moves the joints on the $2 \mathrm{~mm}$ Ti$6 \mathrm{Al}-4 \mathrm{~V}$ body, and the moveable pin, which caused inspection damage to the instrument in the event of a process, is also thought to be a unique design. The microstructure of the welded surface of the material is being discussed in the tool movement as a way to reduce quality at welded junctions. 
Sadoun et al. [6] investigated on friction stir welding (FSW) tool dispensation different surface temperatures effectively measured at the top of the surface during the FSW, and the midpoint of the sample thickness, and the centre at the bottom surface. The results in this case demonstrate an unproductive value of the pin side area, which is defect free in the FSW 7075-O process of the 7075-O AL alloy family, with a welding speed of 50 $\mathrm{mm} / \mathrm{min}$ at $500 \mathrm{rpm}$. With a higher proportion (29.83 percent) of the pin side area formed at the FSW process joint with higher tensile strength, the pin area is the high side of the result, resulting in higher tensile strength in the semi-circular pin. Salloomi et al. [7] (2020) studied the accuracy of finite element simulation to avoid temperature distribution and coercing strain during friction stir welding (FSW) of AA 7075-T651 alloy. Furthermore, the thermal contention conduction process between work parts causes a variety of material characteristics and heat transfer losses are evaluated. Sorger et al. [8] investigated that current high-strength steel has a lower weight without sacrificing load bearing capacity improvement. In order to better retain the qualities of the base material, FSW has joined the HSS in low altitude temples. It has been discovered that the properties of HSS have a wide range of extreme temperatures and cooling rates. HSS was manufactured using a thermomechanically controlled technique and welded by FSW at peak temperatures that were coloured within the treated area. Tarasov et al. [9] conducted an investigation for the diffusion wear mechanism in 1.2344 X40CrMoV5-1 steel 122 CSVTU Research Journal. 2020, Vol. 09, No. 2
FSW equipment. Under temperature, the surface layer of the working layer of specification of iron or aluminium in aluminium alloys increases rapidly, as does the mechanical stress hanging pregrain boundaries under makeup. Chegeni \& Kapranos [10] experimented on the FSW technique, two rolled aluminium plates in the 7075 series are welded together using a coexisting double-side. At $628^{\circ} \mathrm{C}$, both the base plate material and the friction welded area showed deformation after welding heat treatment at the temperature limit. Maa et al. [11] performed on proportional circumstance of the UFG 7075 materials outperform the CG 7075 materials in quality. However, the age-solidifying effect in the UFG 7075 materials isn't as noticeable as it is in the CG 7075 materials, for example, quality enhancement following common maturing or T6 temper. In comparison to CG7075E-sol, the yield quality of tests CG7075-ENag and CG7075-E-T6 improves by $70 \%$ and 160 percent, respectively. The yield quality improvements following common maturing and T6 tempering for the UFG 7075 materials, on the other hand, are 13 percent and 26 percent, respectively. Ambroziak et al. [12] examined on contact welding of various materials, mechanical properties of joints and various configurations of the technique fluctuate significantly. The examination of the aluminium-iron double framework concludes that the procedure's extended duration and high temperatures can result in the formation of intermetallic phases. Different metal mixtures with different qualities can be framed depending on the type of linked materials and the method boundaries. Sivaraj et al. [13] studied using a single pass welding technique, 
friction mix welding for $12 \mathrm{~mm}$ thick moving plates of precipitation solidified, high quality protection grade AA7075T651 aluminium compounds prevailed with no flaws. The malleable qualities of erosion mix welded AA7075-T651 amalgam were decreased by frictional heat, which hastened disintegration. The flexible qualities of contact mix welded AA7075-T651 aluminium compound joints were further reduced by the counterfeit maturation procedure used in this study. The preparation of treatment, which is followed by a counterfeit maturing cycle, is designed to improve the flexible qualities and hardness of rubbing mix welded AA7075 aluminium combination joints.

\section{Effect on microstructure}

Ilangovan et al. [14] studied effects of the hardware nail profile on the microstructure and tractability of grating mix weld dissimilar AA 6061-AA 5086 aluminium composite junctions were investigated, and the following conclusions were reached. The straight round and hollow pin profile instruments, out of the three used, produced cross-sectional full scale level deformities in the mix zone and are thus unavailable for AA 6061 and AA 5086 dissimilar joints. Deformity-free joints were produced by threading and tightening tube-shaped pin profile equipment. Kumar et al. [15] performed in the combination of friction mix welding with boron carbide powder expansion resulted in increased hardness and microstructure refinement in the piece zone. The microstructure of the chunk zone was found to be responsive to pinnacle maturing (T6), retrogression, and RRA post-weld heat medicines. The increased hardness of the weld chunk was attributed to the homogeneous 123 CSVTU Research Journal. 2020, Vol. 09, No. 2 appropriation of reinforcing hastens in the network and molecule reinforcing after RRA treatment with the expansion of boron carbide powder. Rengarajan \& Rao [16] conducted experiment on two different metals, AA7075 and AA6061, where both were welded in T6 circumstances using strong state welding techniques (erosion welding) at varied boundaries and a good holding quality was obtained. With the exception of test 1 , which required ingress and included voids due to low rubbing pressure during welding, all of the instances in the radiography tested. High steamed weight, medium erosion weight, speed, and low consume off length esteems were used to get the highest elasticity of $203 \mathrm{MPa}$. Shah \& Badheka, [17] studied during the FSW process, temperature distributions in the work piece Al 7075 T651 were determined experimentally. Temperatures on the advancing side of the weld were found to be somewhat higher than those on the receding side. Although measuring temperatures near the weld line is extremely challenging, measurements around the rim of the tool shoulder have been attempted. According to the findings, the ideal temperature for a defect-free friction stir weld of $\mathrm{Al} 7075 \mathrm{~T} 651$ is between 375 and 420 degrees Celsius. The experimental results obtained that joints with a $20 \mathrm{~mm}$ shoulder diameter provide the most joint efficiency with sound quality welds.

Bayazid et al. [18] studied the microstructure and mechanical characteristics of FSW and $7075 \mathrm{Al}$ alloys after cyclic solution treatment and artificial ageing. The FSW technique degraded the alloy's mechanical characteristics, particularly in HAZ and TMAZ were 
observed. Without causing aberrant grain growth, the CST homogenised and restored the mechanical characteristics of the joints. The recurrent partial dissolving of large MgZn2 precipitates and production of fine met stable $\mathrm{MgAlCu}$ precipitates was ascribed to the improvement of mechanical characteristics via CST. When compared to the base plate, the retention of the fine grain structure resulted in a significant increase in hardness (39\%), yield stress (11\%), and ultimate tensile strength (10\%) of the joints without a significant change in ductility. Burek et al. [19] investigated apparatus pin works under the most difficult circumstances and is typically useless to wear. The pin's somewhat small components, such as its $4 \mathrm{~mm}$ width, and the massive forces $(5 \mathrm{kN})$ that occur throughout the procedure make it the most vulnerable to wear. Furthermore, string wear increases the risk of injury, which can weaken the apparatus centre. During the welding procedure, the device's face surface and circumferential wear were observed in relation to the welding separation. Controlling pin expansion is therefore critical to ensuring appropriate weld quality boundaries during the procedure. The equipment encountered a break in time during the underlying welding stages, which was reflected in lower quality across the first 40 metres of welding. The qualitative attributes balance out at roughly $6.5 \mathrm{kN}$ after this separation. After 200 metres of welding, the quality of the welds begins to deteriorate by roughly $30 \%$, and the repeatability of the results also begins to deteriorate due to a change in the material's blending states. Chegeni \& Kapranos [20] investigated a contemporaneous twofold sided grinding 124 CSVTU Research Journal. 2020, Vol. 09, No. 2 mix welding approach was used to weld plates of aluminium 7075 composite. Due to the extensive plastic deformity of these welds, a post-weld heat treatment at $628^{\circ} \mathrm{C}$ was conducted in the semi-strong district to see if the resulting microstructures were similar to those seen in semi-strong metal handling. During heat treatment at $628^{\circ} \mathrm{C}$, grains begin to form throughout the material, resulting in homogenous nondendrite microstructures similar to those obtained by thixo-forming. Due to the ultra-fine grain structure developed in the $\mathrm{NZ}$, hardness tests demonstrate that it is higher than that of TMAZ and BM.

Also Rasal [21] experimented it very well may be infer that various kinds of welding procedure can be used so as to weld aluminium compound and steel. Investigation of mechanical properties of the weld, temperature, process boundaries are assumes significant job. The serious issue happens with aluminium and steel weld is the development of intermetallic mixes at the interface. It influences the properties and productivity of the weld. So as to improve the quality of these metals weld middle of the road layers at the interface can be utilized. Chandrana et al. [22] investigated on torque and force utilizations increase when the water head expands during decreased erosion mix welding. When compared to traditional grating mix welding, the lowered erosion mix welding has higher force esteems and force usage. The common weld morphology of onion ring design is achieved during the reduced grating mix welding technique, and the erosion mix welded experiments are not presented.

Gong et al. [23] performed vibration stress relief treatment, followed by the characteristic maturation process, has a 
significant impact on reducing residual pressure-induced distortion in $\mathrm{Al} 7075$ thin-walled parts. According to the findings, vibration stress relief accelerates the redistribution of lingering stressors, changing the disfigurement behaviour of the parts and, as a result, effectively releasing lingering stresses and increasing shape solidity. Kacar et al. [24] investigated on AA7075 effects of maturing temperature, time, and pre-strain on mechanical properties. The basic themes were identified from experiments conducted at mature temperatures of 120 and $160^{\circ} \mathrm{C}$ for 30 minutes, with the amount of precipitation increasing with time. It is seen that the circulation of $\mathrm{MgZn} 2$ scatterings builds the quality. When maturing proceeded at a higher temperature or longer timeframe after the development of MgZn2 encourages, microstructure gets gentler. Cam \& Mistikoglu [25] over viewed the vast majority of FSW contemplates announced in the writing exceptional focused on FSW of Al-combinations, for which the technique is initially evolved. A huge loss of solidarity happens in the weld zone of these compounds after FSW, Table 4, both in the HAZ and SZ. The loss of solidarity in the HAZ district is because of the over aging in this locale because of warmth input This trouble is, be that as it may, inborn to precipitation solidified $\mathrm{Al}$ alloys and experienced in practically all welding forms. Besides, the base metal corruption in FSW isn't as high as that in combination welding forms including higher warmth inputs gave that ideal welding conditions to moderately bring down pinnacle temperatures are utilized.

Shah \& Badheka [27] studied on different distributions identified with FSW 125 CSVTU Research Journal. 2020, Vol. 09, No. 2 delineates the accompanying significant angles identified with FSW. The aluminium compounds for which the process was developed expose a significant amount of FSW considerations. The process has been highlighted for welding of aluminium structures to join a variety of aluminium structures in numerous domains of industry, particularly aviation enterprises. The process is designed to create high-quality welds, and the importance of shoulder to stick distance throughout proportion is also discussed. The use of a bobbin device with an appropriate warmth profile results in a sound weld with substantially reduced contortions, which is especially important when welding bigger plates. Record et al. [28] studied of factual experiments to consider major process boundaries as well as the affectability of working conditions to these procedure boundaries. Spindle speed had no effect on $\mathrm{Z}$ axis power, however $\mathrm{X}$ axis power is influenced by feed rate, followed by pin length, and shaft speed. Shoulder temperature is determined by shaft speed, followed by pin length, plunge profundity, and feed rate.

Singh et al. [29] performed FSW process with mechanical characteristics, and applications of grating mix welding of $\mathrm{Mg}$ combinations have been tended to fundamental ends that can be taken from tool geometry is the most convincing component of FSW process improvement. The tool pin profile, shoulder measurement, and tool material all had a substantial impact on joint quality, and erosion between the tool shoulder and work piece is a key component of warming. The FSW procedure boundary (point of axle or instrument tilt regarding the work piece surface, target profundity 
and hub power, inclusion profundity), notwithstanding the apparatus revolution speed and cross speed, assumes a significant job in delivering sound welds. Ciardiello et al. [30] observed mechanical conduct of cement joints arranged with a mono-part epoxy glue and boron steel substrates has been concentrated concerning five diverse stacking edges from unadulterated tractable to shear tests. Mechanical studies revealed that there is no significant difference between the two distinct circumstances when it comes to reducing the time cycle. This is especially noticeable for the example broken in the test, while analysis revealed that both embraced restoration conditions may be used to demonstrate that the nearness of these particles is uniform.

Chuaiphan \& Srijaroenpramong [31] investigate on broken in the tensile test analysis revealed that both embraced restoration conditions may be used to demonstrate that the nearness of welded aluminium materials is uniform. As a result of it revealing no abnormalities in the weld metal and producing weld joints of high competency structures in all weld metals. The microstructure of the weld metals was consisted of delta-ferrite spread in an austenite framework stage, which was the same; however, for the weld metal, the arrangement of delta-ferrite irregularity was more noticeable for the medium and low warmth input levels. The dendritic length of base metal has a lower pitting consumption potential than the total weld metal, interface zone between the delta-ferrite and austenite, and is thus pushed ahead into the austenite stage.

Devrient et al. [32] studied the arrangement for depicting the dispersing conduct of thermoplastics subject to test 126 CSVTU Research Journal. 2020, Vol. 09, No. 2 materials, thicknesses, and districts of test extraction comparable with the outside of the infusion shaped plates and furthermore comparative with the film entrance was offered. Because of shifting situations with respect to the tiny structure of infusion shaped plates, a method model based on the restricted component strategy for laser transmission welding of thermoplastics dispersing conduct is proposed. The response surface strategy deducted the information gathered by various reproductions to compute weld crease geometries subject to a few process boundaries. Song et al. [33] determined the weld pool created by simulating the temperature field of laser welding is equivalent to the genuine weld and proves the immateriality of the warmth source concept. Confirmation is required due to the laser welding impact of the warm cycle temperature on the steel, the lingering pressure, and the residual bending, but the above analysis also offers significant hypothetical help and premise.

Lessa et al. [34] researched the viability of a two-pass Friction Stir Welding technique on Inconel 625 was established using micro structural representations and mechanical tests, which revealed an improvement in the mechanical characteristics in the weld area when compared to the base materials. In the mix zone, the welding operation modified the microstructure of the Inconel refined grains area, and the FSW procedure induced a transition from a dendritic to an equiaxial microstructure in the Inconel 625 weld. Reisgen et al. [36] performed technique for determining the dynamic consistency of compounds using direct spot-FSW is based on calculations of the fashion power and force at the painless 
turning instrument, as well as the thickness of the mix zone from exploratory micro sections. The numerically based technique allows for distinct attributes for dynamic consistency in the mix zone based on temperature and strain rate at various rotational speed and manufacturing power estimates. The obtained estimates of the dynamic thickness for AA5083 do not contradict the general hypothetical estimates of the property and connect subjectively well with the writing data for the amalgam AA6061.

\section{Weld Zone Response}

Baratzadeh et al. [37] observed welded junctions between AA6082-T6 and AA6063-T6 were delivered based on the enhanced weld boundary of hardness profile of the joint, with the greatest reduced hardness estimation obtained in the weld zone. Micro-structural examined of the divergent lap joint clearly identified, the propelling side being normally stacked in the absence of snoring with over welded by hot treatment in contrast to the mature condition. Weber et al. [38] observed concept of external pressurisation with improved openness successfully broadens the procedure's farthest reaches of liquidbased joining. Chuaiphan \& Srijaroenpramong et al. [39] studied the effect of hydrogen in argon as a shielding gas for welding austenitic tempered is increased in the size of the weld pool during welding as a result of increased warmth input more than when utilising pure argon gas as a shielding gas. The weld dot size has been slightly increased with adjusting heat contribution to the weld pool as well as protective gas is modifying heat contribution to the weld pools between increases in hydrogen gases and speed up. Wang et al. [40] studied on 3D FEM model incorporating the temperature field and the re-enactment results are in good agreement with the exploratory results. The welding temperature field demonstrates that the temperature of the contact surface between the straightforward part and the permeable layer has been broken, and the greatest stream rate in the welding district increases with the expansion of laser power and decreases with the expansion of clipping power in the range of $0-0.24 \mathrm{MPa}$. The replicated weld width considering unpleasant surfaces is unacceptable concurrence can be used to predict the trial after-effects of laser transmission welding considering unpleasant surfaces.

Mannucci et al. [41] performed on vanadium interlayer connected to twofold pass welding occurred in the remaining vanadium embed, HAZ in the unbelted vanadium did not debilitate the addition, and the joint coefficient reached 100\% when compared to the initial covered vanadium. Welds between titanium and vanadium contained cubic growth of martensitic structures in HAZ, while welds between vanadium strong arrangements weakened supplement. The pillar balance of hardening opposing to the farthest reaches position formed columnar structures balance on vanadium created a dissolved zone enlarged. Kuball et al. [42] studied temperature having less of an effect on the strain solidifying the shape of the high nitrogen steel at $200{ }^{\circ} \mathrm{C}$ rather than room temperature results in a significant drop in the actual pressure required to achieve a comparable genuine strain. The temperature impact on yield quality is much higher procedure temperature and the yield quality of the 
high nitrogen steel between room temperature and $200{ }^{\circ} \mathrm{C}$. It demonstrates appropriate precision in temperatures up to $200{ }^{\circ} \mathrm{C}$ and, in any case, causes a critical increase in the grinding factor for the two materials.

\section{Conclusion}

Tool shoulder, pin size and defect stress on the tool causing the flow of plastic heat rate across the work-piece all to affect the weld properties. Tasks on the systematic design of equipment based on scientific principles include calculating flow fields for various tool geometries and calculating tool shoulder dimensions based on tool grips on plasticized materials. Tool pin's cross-sectional geometry and surface features such as threads heat generation rates, axial force on the tool, and material flow tool wear, deformation, and failure have also received significantly more attention in the tool pin than in the tool shoulder. The axial, longitudinal and lateral forces of the equipment can be estimated as functions of process parameters or can be assessed using measured data. The load-carrying capacity of the tool pin is estimated taking into account the maximum stress in the tool pin due to the combined effects of bending and torsion. Research efforts are needed to discover cost-effective and long-lasting tools for the application of FSW to soft materials alloys.

\section{Conflict of Interest}

The authors declare no conflict of interest.

\section{References}

1. Batalha, G.F., Farias, A., Magnabosco, R., Delijaicov, S., Adamiak, M., Dobrzański, L.A. 2012. Evaluation of an $\mathrm{AlCrN}$ coated FSW tool. Journal of Achievements in
Materials and Manufacturing Engineering, 55(2): 607-615.

2. Chen, K.J., Hung. F.Y., Lui, T.S., Shih, Y.R. 2019. Wear inducing phase transformation of plasma transfer arc coated tools during friction stir welding eith AL alloy.journal of engineering: 01-10.

3. Lakshminarayanan, A.K.,

Ramachandran, C.S.,

Balasubramanian, V.,2014.

Feasibility of surface-coated friction stir welding tools to join AISI 304 grade austenitic stainless steel. Defence Technology dx.doi.org/10.1016/j.dt.2014.07.003: 1-11.

4. Li, H., Qin, W., Liu, D., Li, Q., Wu, Y.2017. Design of friction stir welding tools reducing heat flow into spindle. Int J Adv Manuf Technol, DOI 10.1007/s00170-017-0985-7: 18.

5. Fall, A., Fesharaki, M.H., Khodabandeh, A.R., Jahazi, M.2016. Tool Wear Characteristics and Effect on Microstructure in Ti-6Al-4V Friction Stir Welded Joints. Giuseppe Casalino, doi:10.3390/met6110275: 112.

6. Sadouna, A.M., Wagihb, A., Fathyb, A., Essac, A.R.S.,2019. Effect of tool pin side area ratio on temperature distribution in friction stir welding. Results in Physics 15 (2019) 102814: 1-8.

7. Salloomi, K.N., Hussein, F.I., AlSumaidae, S.N.A.2020. Temperature and Stress Evaluation during Three Different Phases of Friction Stir Welding of AA 7075-T651 Alloy. Hindawi Modelling and Simulation in 
Engineering,

doi.org/10.1155/2020/3197813

8. Sorger, G., Sarikka, T., Vilaça, P., Santos, T.G.2018. Effect of processing temperatures on the properties of a high-strength steel welded by FSW. Welding in the World, doi.org/10.1007/s40194-018-0612-8: 01-13.

9. Tarasov, S.Y., Rubtsov, V.E., Kolubaev, E.A.2014. A proposed diffusion-controlled wear mechanism of alloy steel friction stir welding (FSW) tools used on an aluminium alloy. Wear318(2014): 130-134.

10. Chegeni, A.A., Kapranos, P.2017. A Microstructural Evaluation of Friction Stir Welded 7075 Aluminum Rolled Plate Heat Treated to the Semi-Solid State. Metals 2018, 8, 41; doi:10.3390/8010041: 01-09.

11. Maa, K., Wen, H., Hua, T., Topping, T.D., Isheim, D., Seidman, D.N., Lavernia, E.J., Schoenung, J.M. 2014. Mechanical behavior and strengthening mechanisms in ultrafine grain precipitation-strengthened aluminum alloy. Acta Materialia 62 2014: 141-155.

12. Ambroziak, A., Korzeniowski, M., Kustron, P.B., Winnicki, M., SokoBowski, P.B., Harapinska, E. 2014. Friction Welding of Aluminium and Aluminium Alloys with Steel. Hindawi Publishing Corporation Advances in Materials Science and Engineering, (2014): 01-15, doi.org/10.1155/2014/981653.

13. Sivraj, P., Kanagarajan, D., Balasubramanian, V. 2014. Effect of post weld heat treatment on tensile properties and microstructure characteristics of friction stir welded 129 CSVTU Research Journal. 2020, Vol. 09, No. 2 armour grade AA7075-T651 aluminium alloy. Defence Technology 10 (2014): 01-08.

14. Ilangovani, M., Boopathy, S.R., Balasubramanian, V.2015. Effect of tool pin profile on microstructure and tensile properties of friction stir welded dissimilar AA 6061eAA 5086 aluminium alloy joints. Defence Technology 11 2015: 174-184.

15. Kumar, P.K., Reddy, G.M., Rao, S. 2015. Microstructure and pitting corrosion of armour grade AA7075 aluminium alloy friction stir weld nugget zone e Effect of post weld heat treatment and addition of boron carbide. Defence Technology 11 2015: 166-173.

16. Rengarajan, S., Rao, V.S. 2015. Characteristics of AA7075-T6 And AA6061-T6 Friction welded joints. Transactions of the Canadian Society for Mechanical Engineering, Vol. 39 (4) 2015: 845-854.

17. Shah,P.H., Badheka,V. 2016. An experimental investigation of temperature distribution and jointproperties of $\mathrm{Al} \quad 7075 \quad \mathrm{~T} 651$ friction stir welded aluminium alloys. Procedia Technology, 23: 543 - 550.

18. Bayazid, S.M., Farhangi, H., Asgharzadeh, H., Radan, L., Ghahramani, A. Mirhaji, A. 2016. Effect of cyclic solution treatment on microstructure and mechanical properties of friction stir welded 7075 Al alloy. Materials Science \& Engineering A 649/2016: 293-300.

19. Burek, R., Wydrzyński, D., SępWojciech, J., Więckows. 2017. The effect of tool wear on the quality of lap joints between 7075 t6 aluminum alloy sheet metal created 
with the FSW method. Eksploatacja Niezawodnosc Mainten ance and Reliability, 102 Vol. 20, No. 1, 2018. :101-106.

20. Chegeni, A.A., Kapranos, P.2018. A Microstructural Evaluation of Friction Stir Welded 7075 Aluminum Rolled Plate Heat Treated to the Semi-Solid State. Metals 2018, 8, 41: 01-09.

21. Rasal, S. 2017. Welding of Aluminium Alloys 6061-T4 to Stainless steel AISI 304, An Overview. International Conference on Ideas, Impact and Innovation in Mechanical Engineering ICIIIME 2017 ISSN: 2321-8169 Volume: 5 (6): 1775-1780.

22. Chandrana, R., Kumar, S., Santhanamb, V. 2018. Submerged Friction Stir Welding of 6061-T6 Aluminium Alloy under Different Water Heads. Materials Research. 2018; 21(6): 01-11.

23. Gong, H., Sun, Y., Liu, Y., Wu, Y., He, Y., Sun, X., Zhang, M.2018. Effect of Vibration Stress Relief on the Shape Stability of Aluminum Alloy 7075 Thin-Walled Parts. Metals 2019/ 9/ 27: 01-12.

24. Kacar, I., Fahrettin, M.S., Erdema, O.2019. Effects of Aging Temperature, Time, and PreStrain on Mechanical Properties of AA7075. Materials Research, doi.org/10.1590/1980-5373-mr-20190006.

25. Cam, G., Mistikoglu, S. 2014. Recent Developments in Friction Stir Welding of Al-alloys. Journal of Materials Engineering and Performance, DOI: 10.1007/s11665014-0968. 23, (6): 1936-1953.
26. Cai, B., Adams, B.L., Nelson, T.W. 2006. Relation between precipitatefree zone width and grain boundary type in 7075-T7 Al alloy. Acta Materialia 55 (2007): 1543-1553.

27. Shah, P.H., Badheka, V.J.2017. Friction stir welding of aluminium alloys: An overview of experimental findings - Process, variables, development and applications. Materials Design and Applications $0(0): 1-36$.

28. Recor, J.H., Covington, J.L., Nelson, T.W., Sorensenc, D., Webb, B.W. 2007. A Look at the Statistical Identification of Critical Process Parameters in Friction Stir Welding. Welding resurch 86: 97-103.

29. Singh, K., Singh, G., Singh, H. 2018. Review on friction stir welding of magnesium alloys. Journal of Magnesium and Alloys (6)2018 :399416.

30. Ciardiello, R., Greco, L., Miranda, M., Sciullo, F.D., Goglio, L,2020. Experimental investigation on adhesively bonded U-shaped metallic joints using the Arcan test. Journal of Advanced Joining Processes 1.2020/100010.

31. Chuaiphan,W., Srijaroenpramong, L.2020. Effect of hydrogen in argon shielding gas for welding stainless steel grade SUS 201 by GTA welding process. Journal of Advanced Joining Processes 1 (2020) 100016: 01-08.

32. Devrienta, M., Dab, X., Fricka, T. C, Schmidta, M. 2012. Experimental and simulative investigation of laser transmission welding under consideration of scattering. Physics Procedia 39 (2012) 117 - 127. 
33. Song, Y., Wang, Y., Zhang, M.2019. Experimental and Numerical Simulation on Laser welding of High Manganese TWIP980 Steel. Procedia Manufacturing 37 (2019) 385-393.

34. Lessaa, C.R.D.L., Landella, R.M., Bergmanna, L., Kwietniewskib, J.C.E.F., Regulyb, A., Klusemanna, B., Santosa ,A.F.D.2020. Two-Pass Friction Stir Welding of Cladded API X65. Procedia Manufacturing 47: 1010-1015.

35. Afonso, R.M., Alves, L.M., Martins, P.A.F. 2020 Joining by boss forming of rods and tubes to sheets. Journal of Advanced Joining Processes. doi.org/10.1016/j.jajp.2019.100001.

36. Reisgen, U., Schiebahn, A., Sharma, R., Maslennikov, A., Rabe, P., Erofeev, V. 2020. A method for evaluating dynamic viscosity of alloys during friction stir welding. Journal of Advanced Joining Processes 1 (2020) 100002: 01-09.

37. Weber, F., Hahn, M., Tekkaya, A.E. 2020. Joining by die-less hydroforming with outer pressurization. Journal of Advanced Joining Processes 1 (2020) 100014: 01-04.

38. Baratzadeh, F.,Boldsaikhan, E., Nair,R., Burford, D., Lankarani, H. 2020. Investigation of mechanical properties of AA6082-T6/AA6063-T6 friction stir lap welds. Journal of Advanced Joining Processes 1 (2020): 01-07, doi.org/10.1016/j.jajp.2020.100011.

39. Chuaiphan, W., Srijaroenpramong, L.2020. Microstructure, mechanical properties and pitting corrosion of TIG weld joints alternative low-cost austenitic stainless-steel grade 216. 131 CSVTU Research Journal. 2020, Vol. 09, No. 2
Journal of Advanced Joining Processes, S2666-3309(20)30025.

40. Wang, C.Y., Jiang, C.Y., Wang, C.D., Liu, H.H., Zhao, D., Chen, Z.L. 2020. Modeling three-dimensional rough surface and simulation of temperature and flow field in laser transmission welding. Journal of Advanced Joining Processes 1 (2020) 100021: 01-10.

41. Mannucci, A., Tomashchuk, I., Mathieu, A., Bolot, R., Cicala, E., Lafaye, S., Roudeix, C.2020. Use of pure vanadium and niobium/copper inserts for laser welding of titanium to stainless steel. Journal of Advanced Joining Processes 1 (2020) 100022: 01-12.

42. Kuball, C.M., Jung, R., Uhe, B., Meschut, G., Merklein, M.2020. Influence of the process temperature on the forming behaviour and the friction during bulk forming of high nitrogen steel. Journal of Advanced Joining Processes 1 (2020) 100023: 01-09. 